\title{
REVIEW
}

\section{Neurostimulation Methods in the Treatment of Chronic Pain}

\author{
R. ROKYTA ${ }^{1}$, J. FRICOVÁ ${ }^{2}$ \\ ${ }^{1}$ Department of Normal, Pathological and Clinical Physiology, Third Faculty of Medicine, Charles \\ University in Prague, Prague, Czech Republic, ${ }^{2}$ Pain Management Center, First Faculty of Medicine \\ and General University Hospital, Charles University in Prague, Prague, Czech Republic
}

Received March 15, 2012

Accepted April 20, 2012

\section{Summary}

The main neuromodulatory methods using neurostimulation principles are described. It concerns peripheral nerve stimulation (PNS), spinal cord stimulation (SCS), deep brain stimulation (DBS), motor cortex stimulation (MSC), and repetitive transcranial magnetic stimulation (rTMS). For each method the history, pathophysiology, the principles for use and the associated diagnoses are mentioned. Special attention is focused on the most common neuromodulatory invasive methods like SCS and MCS and non-invasive methods such as rTMS. In addition to the positive effects, side effects and complications are described and discussed in detail. In conclusion, neuromodulatory (neurostimulatory) techniques are highly recommended for the treatment of different types of pharmacoresistant pain.
\end{abstract}

\section{Key words}

Pharmacoresistant pain • Neuromodulation • Neurostimulation • Treatment

\section{Corresponding author}

Richard Rokyta, Charles University in Prague, Third Faculty of Medicine, Department of Normal, Pathological and Clinical Physiology, Ke Karlovu 4, 12000 Prague, Czech Republic. Fax:+420 224923 827. E-mail: richard.rokyta@If3.cuni.cz

\section{Introduction}

Pain, in one form or another, has been present throughout the entire history of mankind. Because of its association with many, perhaps most, diseases the treatment of pain has in many ways paralleled the development of the treatment of disease. Therefore, it is not a stretch to declare that pain is an omnipresent part of the human condition. Most pain treatment has come in the form of pharmacotherapy, although other methods have been added over time. These other techniques have included psychotherapy, rehabilitation and over the last fifty years the increasing use of neuromodulation methods. These latter methods are based on the principles of electrical and magnetic stimulation, radiofrequency pulse stimulation and new pump systems which can deliver neuromodulators directly into the intrathecal space.

This article we will focus primarily on neurostimulation methods that use electrical and magnetic stimulation. These methods of neuromodulation find their greatest use and deliver the greatest benefits in patients suffering from pharmacoresistant chronic pain (Fig. 1). Chronic pain is thought to affects $30 \%$ of the population in developed countries, although some authors put the number lower at $10 \%$ while others suggests values as high as $50 \%$.

As mentioned, neurostimulation methods are used primarily for pharmacoresistant chronic pain, when long-term drug therapy is ineffective (Simpson 2003). The use of electricity to modulate pain has a surprising long history (Kozák et al. 2012).

\section{PNS - peripheral nervous stimulation}

History

The first device that provided 'electro-treatment' appeared in 1918 and was designed for electrical stimulation of peripheral nerves. In 1965, Wall and Sweet, electrically stimulated the infraorbital and ulnar nerve. Transcutaneous electrical nerve stimulation 
(TENS) was introduced into practice between the years of 1967-1970 (Stanton-Hicks 2003). While more sophisticated in design, in function, the TENS unit was not dramatically different from earlier devices designed to stimulate the peripheral nervous system (PNS).

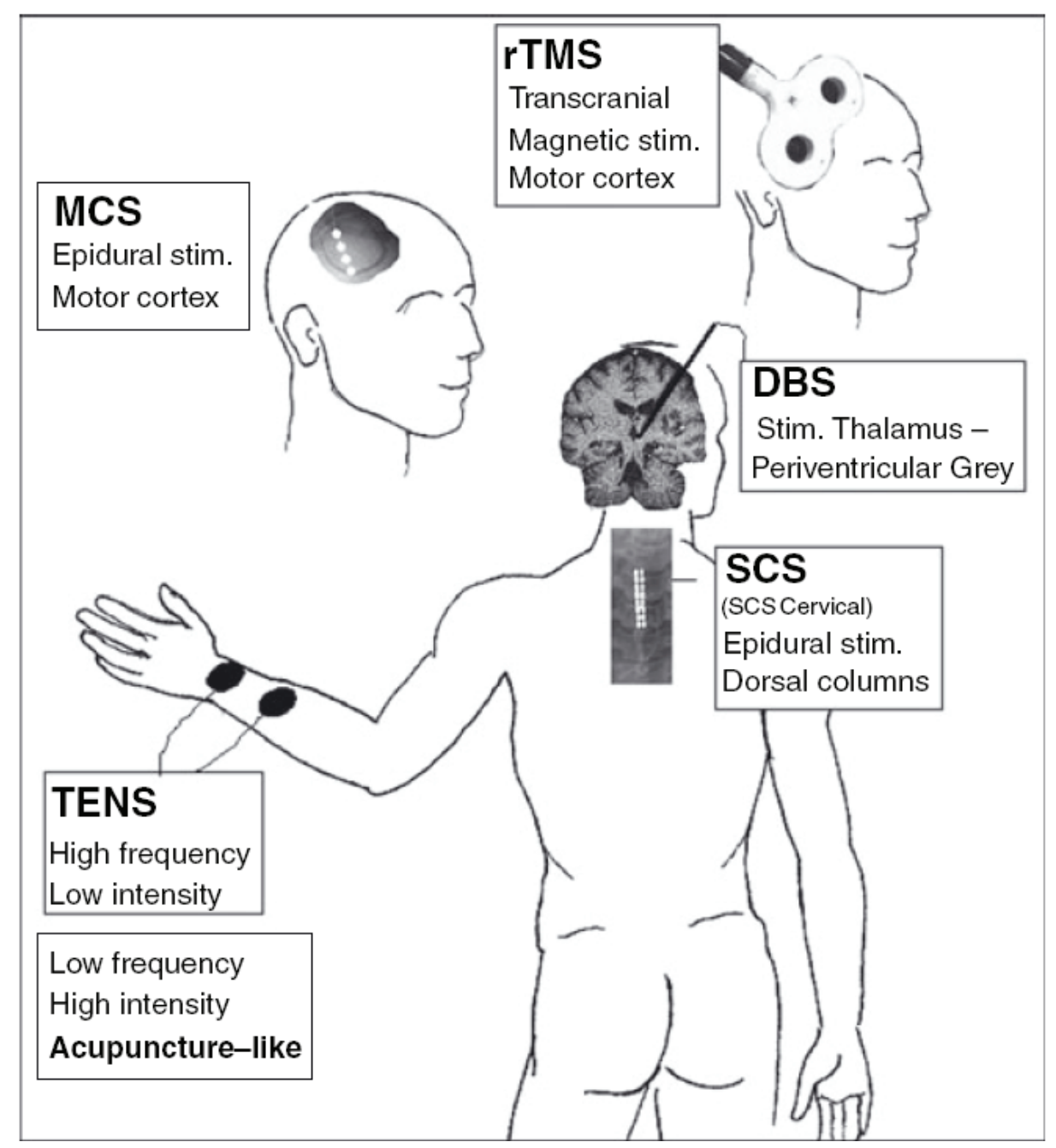

Fig. 1. Overview of neurostimulation methods. PNS - peripheral nervous stimulation, SCS - spinal cord stimulation - stimulation of the dorsal and /or the anterolateral spinal tracts, DBS - deep brain stimulation, MCS - motor cortex stimulation, rTMS - repetitive transcranial magnetic stimulation (This figure was taken from EFNS guidelines from the publications of G. Cruccu et al. 2007.)

\section{Mechanism of action}

Effects of the PNS lie in blocking sodium channels, thereby preventing occurrence of action potentials. The PNS also decreases the excitability of nerve C fibers (Lewis and Racz 1992). Additionally, it seems to modify the release of GABA, CGRP, substance $\mathrm{P}$, adrenaline, serotonin, and alanine (Buschmann and Oppel 1999).

\section{Therapeutic indications}

The method is used for pain and disability along the distribution of a peripheral nerve (Hassenbusch et al. 1996). In the upper extremity, typically stimulated nerves include the $\mathrm{n}$. ulnaris, $\mathrm{n}$. medialis and $\mathrm{n}$. radialis. In the lower extremity the $\mathrm{n}$. tibialis and the n. peroneus are often targets for stimulation. Recently nerves in the head such as the n. occipitalis and the n. vagus (Vanelderen et al. 2010) have been the subject of stimulation.

In many cases, PNS is often combined with SCS (Day 2000, Leak and Ansel 1996).

\section{SCS - spinal cord stimulation}

In SCS the spinal cord is stimulated, most often the dorsal pathways, but sometimes the lateral pathways of the spinal cord are also partially stimulated. 


\section{History}

Shealy, Mortimore and Reswick (Wisconsin, U.S.A.) in 1967 were the first to make reference to the current name of spinal cord stimulation. In particular they were working on stimulating the dorsal columns of the spinal cord testing the 'gate theory' of pain and, appropriately, name the procedure DCEA, or dorsal column stimulatory electro-analgesia. In the beginning it was also called dorsal column stimulation or DCS. From 1970s spinal cord stimulation became the most widely accepted term for this technique. An interesting side note is that in 1973 the method was used by Czech neurosurgeons Beneš, Šlégr and Strnad using an electrostimulator from IKEM Praha. This method is the most commonly used neuromodulatory method and is routinely used in many countries around the world. A second step forward occurred in 2002. It was a very effective method despite the incomplete understanding of its mechanisms of action.

To help clarify the pathophysiological mechanism researchers turned to the 'gate theory'. They found that antidromic conduction stimulation of $A \beta$ fibers in the dorsal columns reduced pain in the stimulated segment. While the theory offers a partial explanation, it cannot fully explain its mechanism, as note by its authors P.D. Wall and R. Melzack, who had proposed the 'gate control theory' in 1965 (Rokyta et al. 2012).

Opioid theory: Another option for explaining the success of SCS is that SCS increases levels of endorphins which are produced mainly in the raphe nuclei and in nuclei of periaqueductal gray (PAG).

Activation of DNIC: Diffuse noxious inhibitor control (DNIC) starts at the subnucleus reticularis dorsalis in the reticular formation of medulla oblongata neurons and ends on the WDR neurons (Wide Dynamic Range) in the spinal cord. At least part of the mechanism of action involve the $\mathrm{GABA}_{\mathrm{B}}$ system, substance $\mathrm{P}$ (protein), and CGRP (calcitonin gene related peptide).

One of the other SCS effects is increased blood flow. The mechanism here is not well understood and is generally associated with stimulation of caudal levels of the cervical cord and rostral levels of the lumbar cord (Mingyuan et al. 2008). The effect is thought to be caused by sympathetic blockade or induced release of calcitonin gene related peptide (CGRP), which acts as a vasodilator in peripheral vascular tissues (Croom et al. 1996, 1997, Tanaka et al. 2001, 2003, Wu et al. 2006, 2007).

The resultant effect is a combination of SCS pain relief and antinociception vasodilation. For clinical purposes, stimulatory frequencies are between 150 to $200 \mathrm{~Hz}$.

\section{Therapeutic indications}

1. Chronic pain, including back pain (Burchiel et al. 1996, North et al. 1993, North et al. 1996, Rokyta et al. 2009, Turner et al. 1995).

2. Neuropathic pain (Oacley 2003)

3. Failed back surgery syndrome - FBSS

4. Complex regional pain syndrome KRBS (Kozák et al. 2000, Wilson et al. 2005)

5. Angina pectoris particularly its refractory form in which SCS is the only effective method (Brodison and Chauhan 1999, Fanciullo 1999, Murray et al. 1999, Osenbach and Haines 2000, TenVaarwerk et al. 1999)

6. Peripheral arterial disease ICHDK.

\section{DBS - deep brain stimulation}

\section{History}

- 1954 Heath, Pool septal stimulation in schizophrenic patients with metastatic carcinomas

- 1966 Ervin et al., stimulation of the caudate nucleus from treatment of facial pain

- 1973 Hosobushi stimulated VPL and VPM of the thalamus and the medial lemniscus

- 1977 Richardson and Akil and Hosobushi used PAG stimulation and released opioids.

- 1983 Benabid stimulation nucleus subthalamicus (corpus Luysi) attenuation of tremor

- 1983 Benabid, Grenoble attempted deep brain stimulation for pain and found that the stimulation of nc. mediodorsalis and nc subthalamic (corpus Luysi) stopped shivering.

Thus was the basis for the use of DBS for treatment of Parkinsonian tremor and tremors in multiple sclerosis.

Mechanism of action: Blockade of nuclei and pathways participating in the management of pain and the release of endogenous opioids.

\section{Therapeutic indications}

Mechanism of action: is antidromic stimulation of dorsal roots causes vasodilation (Amann et al. 2003, Augustinson 1999, Petrakis et al. 1999).

DBS has been used for intractable pain 
especially in the thalamus for intractable pain. It is the main method for the treatment of tremors linked to extrapyramidal movement disorders, especially in Parkinson's disease and multiple sclerosis.

Currently, DBS is used for the treatment of back pain (Hakl et al. 2011). Different parts of the thalamus and other subcortical structures are stimulated during treatment of intractable neuropathic pain; however, this technique is frequently combined with stimulation of the brain's motor cortex, which also reduces pain (Rokyta et al. 2012). DBS has also been used with varying degrees of success in the treatment of fibromyalgia (Blotman and Branko 2007). In such cases the target of simulation is the ACC (anterior cingulate cortex) (Fig. 2).

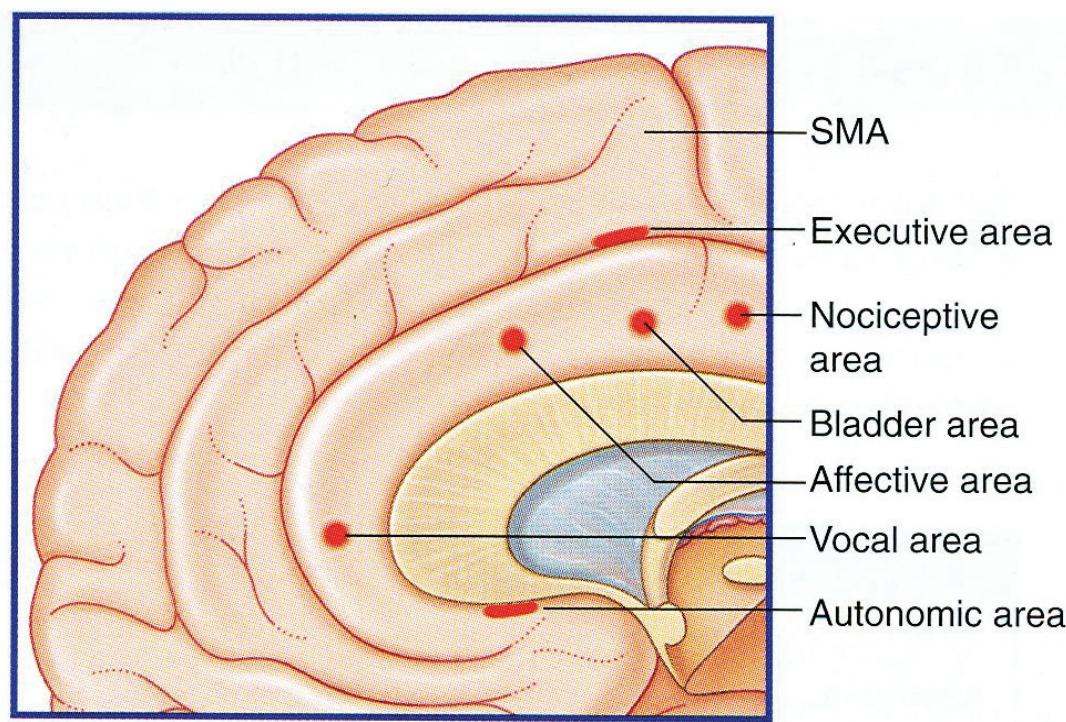

Fig. 2. Functional areas in the anterior cingulate cortex. In this figure are visualised different structures of ACC which are responsible for different functions which include also the painful and nociceptive projection, which are perceived and also regulated from these structures. For the pain and nociception is important the nociceptive area. SMA - supplementary motor area (The figure was taken from Wikipedia (http://cs.wikipedia.org).)

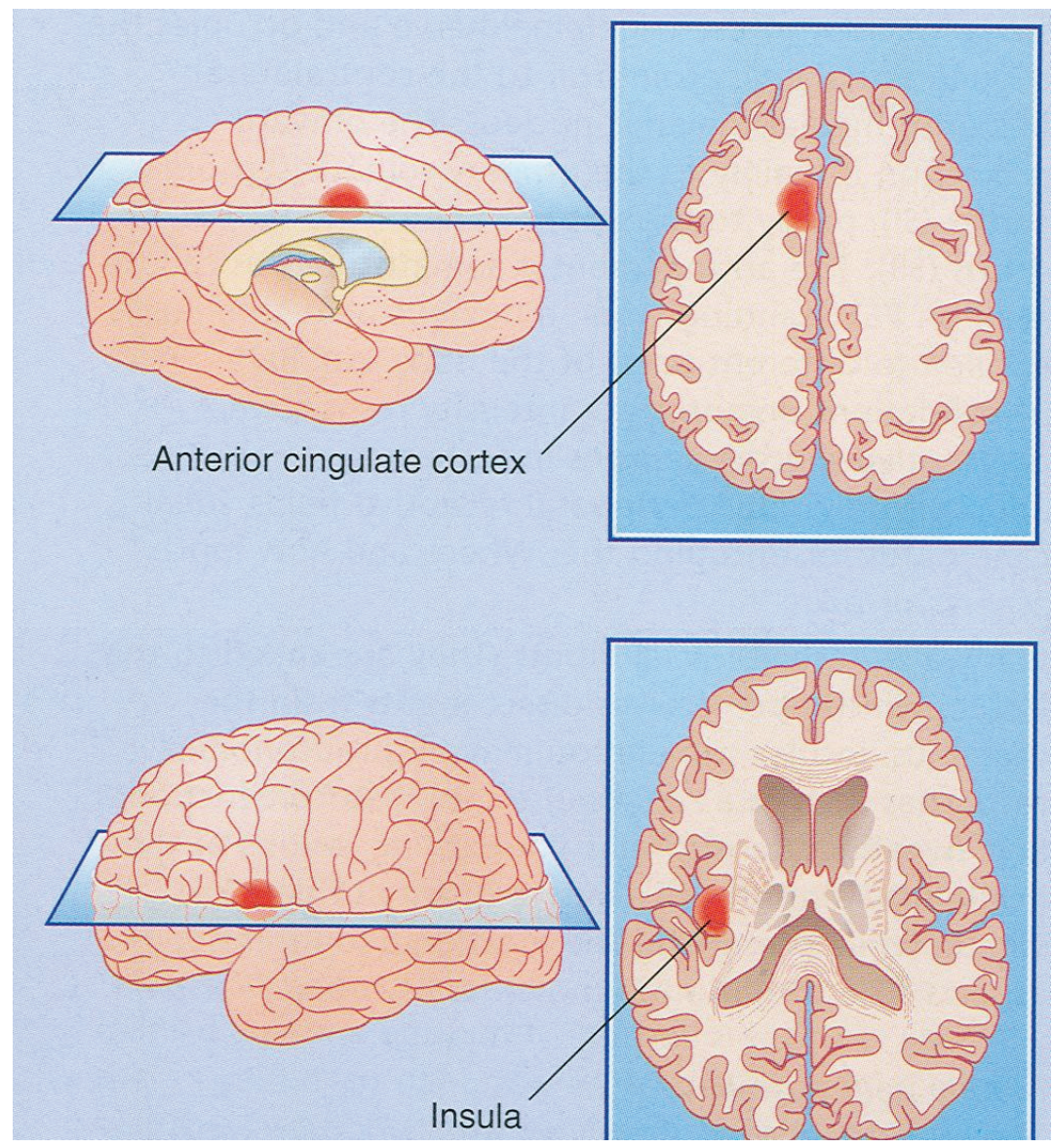

Fig. 3. Anterior cingulate cortex and the insula. Anterior cingulate cortex (ACC) is the centre of the different emotional and somatical inputs like stress, fear, rage, pain and others. (The figure was taken from Wikipedia (http://cs.wikipedia.org).) 


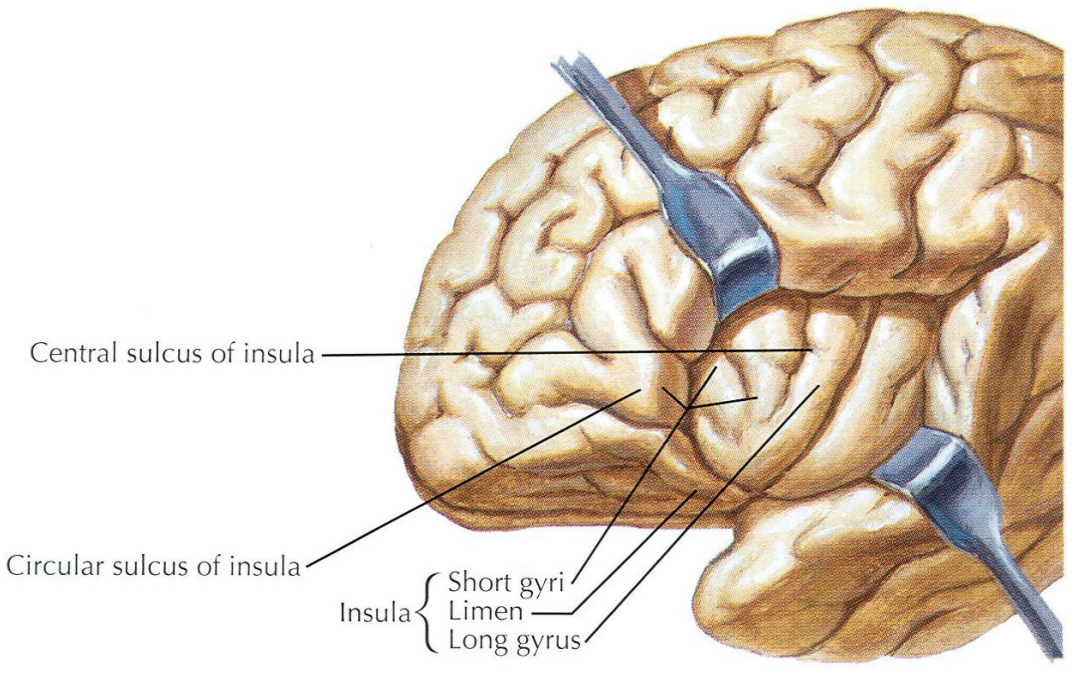

Fig. 4. Insula. Insula is also very important emotional centre in which the pain and nociception are represented. The general influence of insula on emotional and pain processing is very large and important. (The figure was taken from Wikipedia (http://cs.wikipedia.org).)

\section{Deep brain stimulation for pain control}

\section{History}

The theory behind deep brain stimulation was to find places where pain pathways aggregate and then to interrupt the pain pathways through stimulation or destruction of structures associated with pain representation or manifestation. This effort began in the 1960s, mainly under the guidance of Prof. Denise Albe Fessard and Prof. Guiot (1998) at the l'Hôpital Roche in Paris. Unfortunately, the long-term effects fell short of what had been hoped for and even expected.

\section{$D B S$ in the treatment of pain}

Efforts on the use of DBS in the treatment of pain have tended to languish compared to other, newer techniques such as motor cortex stimulation (MCS) and especially spinal cord stimulation (SCS) as well as developments in other methods of neuromodulation (PNS).

Currently, DBS is used mainly in the treatment of back pain (Hakl et al. 2011) (Fig. 3).

Deep brain stimulation has also been used for the treatment of dystonia and trunk pain. For generalized dystonia, the globus pallidus internus is the target of stimulation. Tourette syndrome (a type of dystonia) is a vocal disorder associated with the cingulate of the anterior cortex (ACC) (Fig. 2) in which blood flow to the area is reduced. It is characterized by uncontrollable, annoying short vocal outbursts of individual syllables and occasionally sentences. While in its infancy, DBS has been used to treat Tourette's in a small number of patients (Macinas et al. 2007 and Welter et al. 2008).

\section{Addiction}

Stimulation of the nucleus accumbens and the insula has been used for the treatment of addiction (Fig. 4).

\section{Cognitive functions}

Deep brain stimulation and capsulotomy can have a significant impact on cognitive functions, personality and life of patients with obsessive compulsive disorder. Results so far, generally suggest that it improves the quality of life.

In these patients, stimulation is targeted at the lower thalamic peduncle.

\section{Eating disorders}

Deep brain stimulation can also be used in the treatment of anorexia nervosa as well as other eating disorders. In such cases, a bilateral capsulotomy is performed.

\section{Obesity}

DBS has been used in cases of severe obesity. Stimulation targets various hypothalamic nuclei associated with appetite (lateral hypothalamus) and satiaty (ventromedial hypothalamus).

\section{Epilepsy}

Treatment of epileptic tremors and the shaking associated with multiple sclerosis are perhaps the biggest successes of deep brain stimulation. Stimulation targets the subthalamic nucleus (corpus Luysi) and affects essential tremor, tremor attenuation, improved neurocognitive function all of which lead to an improved quality of life. 


\section{Holmes tremor (cerebellar tremor)}

This type of tremor is rare and is associated with lesions of the brain and the dysfunction such lesion can cause. Additionally, this type of tremor can result from chronic alcoholism or drug abuse. This tremor occurs most frequently in association with hepatic encephalopathy or thyrotoxicosis.

\section{Depression and schizophrenia}

Deep brain stimulation has been used with mixed success for the treatment of both depression and schizophrenia. The goal in schizophrenia is to stimulate the insula.

DBS of the cerebellar cortex is used to suppress aggressive behavior, anxiety and depression.

\section{Technical support of DBS}

One of the keys to DBS is accurate neuronavigation. For complete automation Digitalized Stereotactic Planning and Signal Analysis Tools are used. Deep brain stimulation is combined with magnetoencephalography, but this is difficult, since there are place centers in Europe providing such a combination. In addition there are wireless detection methods for neurotransmitters which can be used during deep brain stimulation in humans (Rokyta et al. 2012).

\section{MCS - motor cortex stimulation}

- 1991 Tsubokawa, Katayama, Yamamoto, Acta neurochirurgica Vienna, central pain after stroke

- Mayerson 1993, Linblom, Linderoth Acta neurochirurgica Vienna

- Trigeminal pain 2001 Beneš, Masopust, Rokyta, Prague central pain (Masopust et al. 2001).

MCS uses $20-50 \mathrm{~Hz}$ stimulation and stimulates the motor cortex (gyrus precentralis).

\section{Mechanism of action}

As the name suggests, MCS targets the brain's motor cortex and stimulates orthodromic conduction in the motor thalamic nuclei, which leads to the released GABA (thalamus contains $90 \%$ GABA neurons). GABA then inhibits the thalamocortical tracks projecting into the posterior gyrus. It inhibits not only sensorydiscriminatory components, but also the emotional affective ones (Simpson and Bjorn 2006, Rokyta et al. 2012).
Therapeutic indications

- postictal pain

- deafferentation pain

- phantom pain

- stump pain

- neuropathic pain

- back pain

- FBSS (failed back surgery syndrome)

- thalamic pain

Stimulation of the motor cortex is currently the third most commonly used method of neurostimulation.

\section{Intravesical electrical stimulation (IVES)}

History

IVES was first used by the Danish surgeon Saxtorph in 1987. Between 1991 and 1998, Jiang found that low-frequency stimulation $(20 \mathrm{~Hz})$ was more effective than high-frequency stimulation.

\section{Mechanism of action}

Increases the affect of autonomic afferents; thereby improving urinary bladder function through increased contraction of the detrusor muscle.

\section{Stimulation of the vagus nerve}

\section{History}

In 1985 a set of small nerve fibers (C fibers) running through the vagus nerve released GABA when stimulated.

\section{Therapeutic use}

Left vagus nerve stimulation has been shown to be therapeutic from those suffering from intractable epilepsy. C fiber stimulation has also been found effective in the treatment of certain types of headaches.

\section{Repetitive transcranial magnetic stimulation - rTMS}

rTMS is a non-invasive, painless stimulation of the cerebral cortex using magnetic fields. Recent studies indicated that this method is able to induce changes in the central nervous system at the cellular level. These include changes in the ionic and metabolic levels. Repetitive transcranial magnetic stimulation (rTMS) has become increasingly popular as a method for treating 
various neuropsychiatric diseases (Fregni and PascualLeone 2007), and the number of clinical trials and clinical applications continues to increase dramatically. Transcranial stimulation can be used with the application of a pulse (single-pulse TMS) applied with a pair of pulses with variable intervals (paired-pulse TMS) or repeating pulses (repetitive) rTMS. The methods are distinguished based on the stimulation frequency used: fast, high-frequency rTMS, which operates at frequencies over $1 \mathrm{~Hz}$ and a slow (lowfrequency rTMS at a frequency rate of $1 \mathrm{~Hz}$ or less). This classification is based on different physiological effects and degrees of risk associated with low and high frequency stimulation. The basic mechanism of action is Faraday induction, which causes an electric field in the membranes of neurons and changes the electrochemical transmembrane potential. Use of rTMS in healthy volunteers it decreased the sensory pain threshold. It was later revealed that this effect was also present in patients with various types of chronic pain (Lefaucheur 2008, Khedr et al. 2007). Studies using imaging techniques have shown that rTMS affects not only the electrochemical changes in the brain, but reorganizes the (changing structure) of the cerebral cortex and other brain areas involved in the development of chronic pain. (Hirayama et al. 2006).
Fundamental principles of the method

- stimulation of the motor cortex is associated with relief from intractable pain of various types syndromes

- stimulation of motor cortex rTMS alters sensory threshold in healthy subjects

- suppress the transmission of sensory information within the spinothalamic tract

- depending on the length of rTMS stimulation, it can induce long-term increases in synaptic transmission

Use rTMS for pain therapy

- test method for MCS

- intractable chronic pain

- neuropathic pain (postherpetic neuralgia)

- pain after strokes

- deafferentation pain (avulsion plexus brachialis) trigeminal neuralgia

- thalamic pain

- atypical oro-facial pain

- spinal stenosis

- low back pain

- phantom pain, thumb pain

(Fig. 1)

\section{Conflict of Interest}

There is no conflict of interest.

\section{References}

ALBE-FESSARD D: Pain - Mechanisms and Basic Treatment. (in Czech) Grada Publishing, Prague 1998.

AMANN W, BERG P, GERSBACH P, GAMAIN J, RAPHAEL JH, UBBINK DT: Spinal cord stimulation in the treatment of non-reconstructable stable critical leg ischaemia: results of the European Peripheral Vascular Disease Outcome Study (SCS-EPOS). Eur J Vasc Endovasc Surg 26: 280-286, 2003.

AUGUSTINSSON L: Spinal cord stimulation in peripheral vascular disease. Eur J Pain 3: 397-399, 1999.

BENEŠ V, ŠLÉGR Z, STRNAD M: Electrostimulation rear spinal cords in the treatment of pain. (in Czech) Journal of Czech Physicians 113: 1565-1568, 1973.

BLOTMAN F, BRANCO J: Fibromyalgia daily aches and pain. Privat, Toulouse, 2007.

BRODISON A, CHAUHAN A: Spinal-cord stimulation in management of angina. Lancet 354: 1748-1749, 1999.

BURCHIEL KJ, ANDERSON VC, BROWN FD, FESSLER RG, FRIEDMAN WA, PELOFSKY S, WEINER RL, OAKLEY J, SHATIN D: Prospective, multicenter study of spinal cord stimulation parameters for relief of chronic back and extremity pain. Spine 21: 2786-2794, 1996.

BUSCHMANN D, OPPEL F: Peripheral Nervenstimulation. (in German) Schmerz 13: 113-120, 1999.

CRUCCU G, AZIZ TZ, GARCIA-LARREA L, HANSSON P, JENSEN TS, LEFAUCHEUR JP, SIMPSON BA, TAYLOR RS: EFNS guidelines on neurostimulation therapy for neuropathic pain. Eur J Neurol 14: 952-970, 2007.

DAY M: Neuromodulation: spinal cord and peripheral nerve stimulation. Curr Rev Pain 4: 374-382, 2000.

FANCIULLO GJ, ROBB JF, ROSE RJ, SANDERS JH: Spinal cord stimulation for intractable angina pectoris. Anesth Analg 89: 305-306, 1999. 
FREGNI F, PASCUAL-LEONE A: Technology insight: noninvasive brain stimulation in neurology - perspectives on the therapeutic potential of rTMS and tDCS. Nat Clin Pract Neurol 3: 383-393, 2007.

HAKL M ET AL.: Pain. (in Czech) Mladá Fronta, Prague, 2011.

HASSENBUSCH SJ, STANTON-HICKS M, SCHOPPA D, WALSH JG, COVINGTON EC: Long-term results of peripheral nerve stimulation for reflex sympathetic dystrophy. J Neurosurg 84: 415-423, 1996.

HIRAYAMA A, SAITOH Y, KISHIMA H, SHIMOKAWA T, OSHINO S, HIRATA M, KATO A, YOSHIMINE T: Reduction of intractable deafferentation pain by navigation-guided repetitive transcranial magnetic stimulation of the primary motor cortex. Pain 122: 22-27, 2006.

HOUDEK M ET AL.: Neuromodulation. (in Czech) Grada Publishing, Prague, 2007.

KHEDR EM, KOTB H, KAMEL NF, AHMED MA, SADEK R, ROTHWELL JC: Longlasting antalgic effects of daily sessions of repetitive transcranial magnetic stimulation in central and peripheral neuropathic pain. $J$ Neurol Neurosurg Psychiatry 76: 833-838, 2005.

KOZÁK J, NERADILEK F, ČERNÝ R: Complex regional pain syndrome. (in Czech) Bolest 3 (Suppl 1): 114-120, 2000.

KOZÁK J, VRBA I, MASOPUST V, ROKYTA R, FRICOVÁ J: Neuromodulation in the treatment of chronic pain. (in Czech) In: Bolest. ROKYTA R, KRŠIAK M, KOZÁK J (eds), Tigis, Prague 2012.

LEAK W, ANSEL A: Neural stimulation: spinal cord and peripheral nerve stimulation. In: Pain Medicine: A Comprehensive Review. RAJ P (ed), Mosby, St Louis, 1996: 327-333.

LEFAUCHEUR JP: Use of repetitive transcranial magnetic stimulation in pain relief. Expert Rev Neurother 8: 799-808, 2008.

LEWIS R, RACZ G: Peripheral Nerve Stimulation - Surgical Technique Laptop. Medtronic, 1992.

MASOPUST V, BENEŠ V, NETUKA D, POLLIN B, ROKYTA R, STEJSKAL V: Stimulation of motor cortex in the treatment of chronic talamic pain. (in Czech) Bolest 4: 91-94, 2001.

MURRAY S, CARSON KGS, EWINGS PD, COLLINS PD, JAMES MA: Spinal cord stimulation significantly decreases the need for acute hospital admission for chest pain in patients with refractory angina pectoris. Heart 82: 89-92, 1999.

NORTH RB, KIDD DH, ZAHURAK M, JAMES CS, LONG DM: Spinal cord stimulation for chronic, intractable pain. Two decades experience. Neurosurgery 32: 384-395, 1993.

OAKLEY JC: Spinal cord stimulation for neuropathic pain. Pain research and clinical management. Electrical stimulation and the relief of pain. Elsevier, Amsterdam, 2003, pp 87-110.

OSENBACH RK, HAINES SJ: Spinal cord stimulation for the treatment of refractory angina pectoris. Crit Rev Neurosurg 9: 394-406, 1999.

PETRAKIS IE, SCIACCA V: Spinal cord stimulation in critical limb ischemia of the lower extremities: our experience. J Neurosurg Sci 43: 285-293, 1999.

ROKYTA R, KRŠIAK M, KOZÁK J (eds): Pain (Pain Management Monograph). (in Czech) Tigis, Prague, 2006.

ROKYTA R, KRŠIAK M, KOZÁK J (eds): Pain (Pain Management Monograph). (in Czech) Tigis, Prague, 2012.

ROKYTA R ET AL.: Back pain. (in Czech) Adela, Pilsen, 2009.

SIMPSON BA: Selections of patients and assessment. In: Electrical Stimulation and the Relief of Pain. Elsevier, Amsterdam, 2003, pp 161-182.

SIMPSON BA, BJORN A: Spinal cord and brain stimulation. In: Wall and Melzack's Textbook of Pain. 5th Edition. Churchill Livingstone, London, 2006.

STANTON-HICKS M: Transcutaneous and peripheral nerve stimulation. In: Electrical Stimulation and the Relief of Pain. Pain Research and Clinical Management, the 15th volume. BA SIMPSON (ed), Elsevier, Amsterdam, 2003, pp 37-56.

TENVAARWERK IA, JESSURUN GA, DEJONGSTE MJ, ANDERSEN C, MANNHEIMER C, ELIASSON T, TADEMA W, STAAL MJ: Clinical outcome of patients treated with spinal cord stimulation for therapeutically refractory angina pectoris. Heart 82: 82-88, 1999.

TURNER JA, LOESER JD, BELL KG: Spinal cord stimulation for chronic low back pain: a systematic literature synthesis. Neurosurgery 37: 1088-1095, 1995. 
VANELDEREN P, LATASTER A, LEVY R, MEKHAIL N, VAN KLEEF M, VAN ZUNDERT J: Occipital neuralgia. Pain Pract 10: 137-144, 2010.

Wikipedia (http://cs.wikipedia.org)

WILSON PR, STANTON-HICKS M, HARDEN RN (eds): CRPS: Current Diagnosis and Therapy. IASP Press, Seattle, 2005, pp 19-27. 